\title{
Discharge less than 6 hours after robot-assisted total laparoscopic hysterectomy-is it feasible?
}

\author{
Jakob Graves Rønk Dinesen • Birgit Hessellund • Lone Kjeld Petersen
}

Received: 22 May 2014 / Accepted: 24 November 2014 /Published online: 13 December 2014

(C) Springer-Verlag Berlin Heidelberg 2014

\begin{abstract}
The benefits of fast track regimes, i.e. reduction in hospital stay and minimization of postoperative complications, have led to their widespread use. This study tested the feasibility of a fast track programme based on robot-assisted laparoscopic hysterectomy in which patients were discharged from a day care unit within $6 \mathrm{~h}$ after the operation. We enrolled 22 patients. Preoperatively, all patients were carefully informed. All patients except two could be discharged on the same day. Pain during the first $24 \mathrm{~h}$ was not a problem. No readmissions occurred within the first 30 days after the surgery. This small series of robot-assisted laparoscopic hysterectomy demonstrates that the postoperative hospital stay could be reduced and that this procedure could be carried out in a day surgery unit. Preparing the patients for surgery in the day unit is an important part of a successful fast track regimen.
\end{abstract}

Keywords Robot-assisted surgery · Total laparoscopic hysterectomy $\cdot$ Fast track programme

\section{Introduction}

The benefits of fast track regimes, i.e. reduction in hospital stay and minimization of postoperative complications, have led to widespread use of the programmes. Many separate factors such as providing the patient with extensive preoperative information, optimal postoperative pain relief, early feeding and mobilization as well as minimal invasive surgical procedures are central features of these programmes.

J. G. R. Dinesen • B. Hessellund • L. K. Petersen $(\bowtie)$

Department of Gynecology and Obstetrics,

Aarhus University Hospital, 8200 Aarhus N, Denmark

e-mail: lonpeers@rm.dk
Hysterectomy is still a very frequently performed gynaecologic procedure. The vaginal approach is considered the most cost effective, [1] but if there is a need for combining the hysterectomy with removal, the fallopian tubes and the ovaries, the vaginal approach may be inappropriate. Consequently, some gynaecologists consider oophorectomy a contraindication to the vaginal hysterectomy [2].

Introducing the laparoscopic hysterectomy solved this problem. Robot-assisted laparoscopic hysterectomy is now widely used even though the operative costs of performing this procedure are significantly higher than those of total laparoscopic hysterectomy $[1,3]$. On the other hand, the robotic method seems less traumatic. Postoperative pain is reported the same or reduced in patients, who have undergone a robot-assisted laparoscopic hysterectomy compared to the laparoscopic hysterectomy $[4,5]$.

The increased costs of the laparoscopic techniques for hysterectomy may be explained by longer operating time and expensive instruments. On the other hand, the benefits of the minimal invasive procedures have reduced the length of hospital stay. Consequently, patients treated by laparoscopic hysterectomy may be discharged within $24 \mathrm{~h}$ after the operation $[6,7]$ and the postoperative setting is redefined to outpatient care.

A day care unit can be defined in different ways, and the working hours differ from day time to $24 \mathrm{~h}$ of service. The aim of this study was to test the feasibility of a fast track programme based on robot-assisted laparoscopic hysterectomy in which patients were discharged from a day unit within $6 \mathrm{~h}$ after the operation.

\section{Material and methods}

All patients, who were scheduled for a total laparoscopic hysterectomy (TLH) at the department of Gynecology, 
University Hospital of Aarhus, were candidates for the robotassisted total laparoscopic hysterectomy (RTLH) fast track programme. All surgeons are fellowship-trained gynaecologic oncologists. The setup required the use of 5 ports, a $12-\mathrm{mm}$ camera port, three 8-mm ports (robot instruments) and a 12$\mathrm{mm}$ assistant port. Standard robotic monopolar shears and bipolar forceps were used. V-loc suture were used for closing the vaginal cuff. Exclusion criteria were performance status (ASA $3+$ ), age $>80$. Twenty-two patients were enrolled, and their characteristics are summarized in Table 1. Indications for hysterectomy were persistent dysplasia $(n=5)$, prophylactic operation due to genetic predisposition $(n=12)$, atypical endometrial hyperplasia $(n=2)$, low stage endometrial cancer $(n=2)$ and heavy menstrual bleeding $(n=1)$.

Preoperatively, all patients were carefully instructed about procedures and the postoperative course. They had metronidazole $(1000 \mathrm{mg})$ for vaginal disinfection the night before the operation and $1000 \mathrm{mg}$ for rectal administration $2 \mathrm{~h}$ before the operation.

Patients were walked to the operation room and given general anaesthesia. All were given cefuroxime $(1500 \mathrm{mg})$, dexamethasone ( $8 \mathrm{mg}$ ) and ondansetron $(4 \mathrm{mg})$ intravenously before the operation started and morphine $(10 \mathrm{mg})$ approximately 1 hour before ending the operation. Total intravenous anaesthesia (TIVA), without $\mathrm{N} 2 \mathrm{O}$ with propofol/remifentanil, morphine and toradol, was used. A routine RTLH was performed including intraabdominal closure of the vaginal vault. Ropivacaine $(50 \mathrm{mg})$ was injected intraperitoneally before closure of the laparoscopic port incisions, and a total of $20 \mathrm{mg}$ of Ropivacaine were injected in the subcutis and fascia around the ports. Intravenous ketorolac $(30 \mathrm{mg})$ was administrated at the end of the operation. The bladder catheter was removed at the end of the operation

After transmission to the recovery ward, patients rested in bed for $2 \mathrm{~h}$ before mobilization was undertaken. Early feeding was encouraged.

Postoperatively, patients were given ibuprofen $(400 \mathrm{mg})$ and paracetamol $(1000 \mathrm{mg})$ four times a day starting $8 \mathrm{~h}$ after the operation. All patients had oxycodone hydrochloride $(10 \mathrm{mg})$ and ondansetron $(4 \mathrm{mg})$ as rescue medicine.

Table 1 Patients' characteristics (median (range))

\begin{tabular}{ll}
\hline & Median (range) \\
Age-years & $53(34-73)$ \\
Body mass index & $25(19-42)$ \\
Operating time "skin-to-skin time" (minutes) & $82(35-170)$ \\
Estimated blood loss (mL) & $30(10-100)$ \\
Conversion to open surgery & 0 \\
Length of hospital stay after the operation (minutes) & $225(150-270)$ \\
Readmission & 0 \\
Opoid after discharge & 3 patients \\
\hline
\end{tabular}

All patients were informed about free access to the ward during the week after the operation. They could contact the department by phone at any time, and patients could be readmitted at any time, if necessary. A nurse phoned all patients the day after the operation. Patients were systematically interviewed at this time regarding postoperative nausea and vomiting (PONV), pain and their needs for antiemetics or opoids. At the end of the phone call, they were invited to call the department if any problems should arise within the next week.

\section{Results}

The RTLH was combined with bilateral removal of the adnexa in all patients except one.

The operation time is given in Table 1. A body mass index exceeding 40 was associated with markedly longer operation time.

All patients except two could be discharged before the day unit closed. In both patients, the reason for nondischarge was dizziness and a general feeling of anxiety. The patients stayed at the hospital for observation until the next morning without further examinations or treatment.

Pain within the first $24 \mathrm{~h}$ was not a problem. All patients completed the recommended pain regime and only three patients needed opoids after discharge. One patient had to continue this treatment for more than $24 \mathrm{~h}$ after the operation.

PONV after discharge was reported by 6 patients, but only four patients needed antiemetic medicine during the first $24 \mathrm{~h}$ after discharge.

One patient was seen in the out-patient clinic within the first week. An infection over the vaginal vault was diagnosed and treated with antibiotics. When the patients were interviewed by phone on the day after the operation, all felt well, were mobilized and had started eating. All patients were offered second interview within a week after the operation, but no one needed an extra telephone call.

No readmission occurred within the first 30 days after the operation.

\section{Discussion}

This small series of robot-assisted total laparoscopic hysterectomy demonstrates that the postoperative hospital stay could be reduced and that this procedure could be carried out in a day surgery unit. Thus, $91 \%$ of the patients could be discharged as planned in less than $6 \mathrm{~h}$ after the operation without any readmissions. Although the length of hospital stay has been generally reduced to 1 to 2 days after RTLH $[8,9]$, this is, to the best of our knowledge, the 
first report of discharge within a few hours after completion of the operation.

Successful assignment of laparoscopic surgical procedures to day units requires careful selection of patients. One important factor is the risk of conversion to open surgery. Consistent with a meta-analysis demonstrating lower conversion rate in RTLH compared to the TLH [8], conversion was not needed in any patients in our study group. A high body mass index was associated with an increased operating time and a higher conversion rate for open surgery in patients who were treated by radical prostatectomy [10]. Although such factors may normally disqualify a patient from a day surgery unit, obese patients with a high rate of comorbidity may in fact benefit the most from the fast track regimen and the reduced postoperative complication rate.

Whether hysterectomy in day units can be generally undertaken in elderly patients remains to be shown. In our study, the two patients $>70$ years of age were discharged within the time limits along with younger patients. Similar results have been obtained in general surgery. Thus, there were no significant differences in length of hospital stay or 30-day readmission rate were demonstrated when younger patients were compared to those $>70$ years [11].

Despite a longer operation time and expensive instruments, the overall hospital costs were significantly lower for robotics compared with hysterectomy performed before the robot era [12]. Thus, the expense of robot-assisted hysterectomies may be balanced by the reduced costs in the postoperative period. The fact that RTLH is associated with a decrease in surgical complications [8] and that fast track regimens are generally associated with a decrease in postoperative complications may positively influence the total expenses.

Preparing the patients for a day surgery unit is an important part of a successful fast track regime. Patients should be informed about normal symptoms in the postoperative period including the high incidence of PONV (80\%) after laparoscopic gynaecologic operations [13]. Apart for the careful information given all patients in our study group, rescue medicine was handed out before discharge - oxycodone hydrochloride and ondasetron for self administration. The low incidence of delayed PONV in this study may at least partly be explained by a low consumption of opoids in the postoperative period combined with an effective antiemetic treatment. Our results were encouraging compared to rates of delayed PONV on $47 \%$ within the period from 2 and $24 \mathrm{~h}$ after gynaecologic laparoscopy [14].

The two patients who could not be treated in the day unit were both nervous but without any objective findings. Indeed, no further examinations or treatment was undertaken within the prolonged hospital stay in these two patients.

The low need for readmission or extra visits in the outpatient clinic may indicate well prepared and informed patients. Moreover, the routine nurse phone call on the first postoperative day may prevent readmissions as patients could ask questions and be reassured or guided in case of unexpected symptoms or anxiety. Patients had free access to call the department $24 \mathrm{~h}$ a day for 7 days after the operation, but only one patient called once.

In conclusion, discharge within $6 \mathrm{~h}$ after robot-assisted total laparoscopic hysterectomy is feasible and does not lead to readmission. Patients must be well informed and prepared carefully in order to secure a successful introduction of this fast track regimen. Follow-up by nurse-led phone calls the day after the operation may add to the patients' feeling of security and prevent readmissions or visits in the out-patient clinic.

Acknowledgments All procedures followed were in accordance with the ethical standards of the responsible committee on human experimentation and with the Helsinki Declaration of 1975, as revised in 2000. Informed consent was obtained from all patients for being included in the study.

Conflict of interest Jakob G.R. Dinesen, Birgit Hessellund and Lone Kjeld Petersen declare that they have no conflict of interest.

\section{References}

1. Dayaratna S, Goldberg J, Harrington C, Leiby BE, McNeil JM (2014) Hospital costs of total vaginal hysterectomy compared with other minimally invasive hysterectomy. Am J Obstet Gynecol 210(2):120e1-120e6

2. McCracken G, Lefebvre GG (2007) Vaginal hysterectomy: dispelling the myths. J Obstet Gynecol Can 29:424-428

3. Rosero EB, Kho KA, Joshi GP, Giesecke M, Schaffer JI (2013) Comparison of robotic and laparoscopic hysterectomy for benign gynecologic disease. Obstet Gynecol 122(4):778-786

4. Leitao MM Jr, Malhotra V, Briscoe G, Suidan R, Dholakiya P, Santos K, Jewell EL, Brown CL, Sonoda Y, Abu-Rustum NR, Barakat RR, Gardner GJ (2013) Postoperative pain medication requirements in patients undergoing computer-assisted ("Robotic") and standard laparoscopic procedures for newly diagnosed endometrial cancer. Ann Surg Oncol 20(11):3561-3567

5. El Hachem L et al (2013) Postoperative pain and recovery after conventional laparoscopy compared with robotically assisted laparoscopy. Obstet Gynecol 121(3):547-553

6. Lee SJ, Calderon B, Gardner GJ, Mays A, Nolan S, Sonoda Y, Barakat RR, Leitao MM Jr (2014) The feasibility and safety of same-day discharge after robotic-assisted hysterectomy alone or with other procedures for benign and malignant indications. Gynecol Oncol 133(3):552-555

7. Lassen PD, Moeller-Larsen H, DE Nully P (2012) Same-day discharge after laparoscopic hysterectomy. Acta Obstet Gynecol Scand 91(11):1339-1341

8. Scandola M, Grespan L, Vicentini M, Fiorini P (2011) Robotassisted laparoscopic hysterectomy vs traditional laparoscopic hysterectomy: five metaanalyses. J Minim Invasive Gynecol 18(6):705-715

9. Orady M, Hrynewych A, Nawfal AK, Wegienka G (2012) Comparison of robotic-assisted hysterectomy to other minimally invasive approaches. JSLS 16(4):542-548

10. Herman MP, Raman JD, Dong S, Samadi D, Scherr DS (2007) Increasing body mass index negatively impacts outcomes following robotic radical prostatectomy. JSLS 11(4):438-442 
11. Keller DS, Lawrence JK, Nobel T, Delaney CP (2013) Optimizing cost and short-term outcomes for elderly patients in laparoscopic colonic surgery. Surg Endosc 27(12):4463-4468

12. Lau S, Vaknin Z, Ramana-Kumar AV, Halliday D, Franco EL, Gotlieb WH (2012) Outcomes and cost comparisons after introducing a robotics program for endometrial cancer surgery. Obstet Gynecol 119(4):717-724
13. Eriksson H, Korttila K (1996) Recovery profile after desflurane with or without ondansetron compared with propofol in patients undergoing outpatient gynecological laparoscopy. Anesth Analg 82:533-538

14. Jung WS, Kim YB, Park HY, Choi WJ, Yang HS (2013) Oral administration of aprepitant to prevent postoperative nausea in highly susceptible patients after gynecological laparoscopy. J Anesth 27(3): 396-401 